\title{
Produção de forragem de populações de azevém anual no estado do Rio Grande do Sul
}

\author{
Ricardo Antunes Flores ${ }^{1}$, Miguel Dall'Agnol ${ }^{2}$, Carlos Nabinger², Daniel Portella Montardo³ \\ 1 Programa de Pós-graduação em Zootecnia - UFRGS, Porto Alegre - RS. \\ 2 Departamento de Plantas Forrageiras e Agrometeorologia - UFRGS. Endereço: Bento Gonçalves, 7712, CEP: 91540-000 - Porto Alegre - RS. \\ ${ }^{3}$ Embrapa Pecuária Sul - BR 153 Km 595, CEP: 96401-970 - Bagé - RS.
}

RESUMO - Este trabalho foi conduzido com o objetivo de avaliar a produção e a distribuição estacional de populações locais de azevém em comparação ao cultivar comercial Comum-RS. Foram realizados em 2004 dois experimentos em duas regiões diferentes do Rio Grande do Sul: Eldorado do Sul (EEA) e Veranópolis (EEV). A produção de forragem foi avaliada em sete populações de azevém anual, um cultivar uruguaio (LE-284), um da Nova Zelândia (Eclipse) e o cultivar Comum-RS, totalizando dez tratamentos. O delineamento experimental utilizado foi o de blocos casualizados, com quatro repetições. Foram realizados vários cortes, seguidos da separação morfológica e secagem visando à avaliação dos teores de matéria seca de folhas e de matéria seca total. A produção de azevém variou significativamente entre as populações avaliadas, indicando a existência de uma grande variação dentro da espécie, sobretudo quanto à distribuição da produção de forragem ao longo do ciclo de crescimento. Em ambos os locais, constatou-se a existência de populações com rendimento superior aos dos cultivares comerciais avaliados, especialmente o Comum-RS, indicando possibilidade de obtenção de novos cultivares a partir das populações localmente adaptadas.

Palavras-chave: Lolium multiflorum, melhoramento genético, populações, seleção

\section{Forage production of annual ryegrass populations in the state of Rio Grande do Sul, Brazil}

\begin{abstract}
The objective of this work was to evaluate forage production and seasonal distribution of locally adapted ryegrass populations in comparison to commercial cultivars. Two experiments were carried out in two different locations of Rio Grande do Sul (Eldorado do Sul - EEA and Veranópolis - EEV), in 2004. Forage production of seven annual ryegrass populations, one Uruguayan cultivar (LE-284), one New Zealand cultivar (Eclipse) were compared to the commercial cultivar, in a total of ten treatments. The experimental design was a randomized block with four replications. Several cuts were performed, followed by morphologic separation of plant parts and drying in order to evaluate dry matter yield of leaves and total dry matter. Ryegrass production varied considerably among populations, indicating the existence of a great variation among them, especially regarding forage seasonal distribution along the growth cycle. At both locations, superior populations were observed in terms of forage production when compared to commercial cultivars, especially the Comum-RS, indicating the possibility of obtaining new cultivars of ryegrass from the locally adapted populations.
\end{abstract}

Key Words: genetic improvement, Lolium multiflorum, populations, selection

\section{Introdução}

As pastagens nativas são a principal fonte de alimentação da bovinocultura de corte no Rio Grande do Sul (RS) e apresentam bom valor forrageiro na estação quente, porém, durante o inverno, não crescem, ficam envelhecidas e crestadas por geadas e não suprem as necessidades para manutenção do peso dos animais. Nessas condições, os animais ganham peso durante a primavera e o verão, mas perdem 30 a 50\% do ganho durante a estação fria (Santos et al., 2002).
Uma das alternativas para amenizar o vazio forrageiro no período frio do ano no Rio Grande do Sul é a utilização de pastagens hibernais. O azevém anual (Lolium multiflorum Lam.) é uma das espécies mais cultivadas e pode ser utilizado isoladamente ou em misturas. Além disso, o uso de pastagens cultivadas de inverno é uma boa alternativa para compor sistemas de integração lavourapecuária, pois o estado do Rio Grande do Sul possui área de aproximadamente seis milhões de hectares cultivados com soja (Glycine max) e milho (Zea mays), dos quais $12 \%$ 
são cultivados com trigo no inverno e o restante é pouco aproveitado (CONAB, 2007). As forrageiras de estação fria são fundamentais para uma agricultura sustentável e representam a base alimentar de ruminantes nas regiões de clima temperado de todo o mundo (Nelson \& Moser, 1994).

Gillet (1984) classificou o azevém como uma gramínea forrageira de fácil implantação e utilização. É uma espécie muito versátil, que pode ser utilizada em pastagem cultivada de inverno, como melhoradora de pastagens naturais ou como cobertura visando ao plantio direto na primavera.

Em ambientes temperados,o melhoramento do azevém tem sido realizado visando à obtenção de cultivares com tolerância ao frio, o aumento na produção de forragem e seus componentes nutricionais e o aumento na produção de sementes. Entre os objetivos mais recentes, destacam-se a tolerância ao alumínio e a resistência a diversas doenças. Por ser uma planta alógama, fornece vantagens ao melhorista, em virtude da alta heterozigose nos indivíduos, resultando em ampla variabilidade genética, que pode ser utilizada no melhoramento (Nelson, 1995; Nelson et al., 1997). O melhoramento genético do azevém no Brasil tem como finalidade o desenvolvimento de cultivares mais produtivos, de ciclo mais precoce e que sejam adaptados a diferentes condições edafoclimáticas. Portanto, objetivou-se avaliar a produção e a distribuição estacional de populações locais de azevém, em comparação ao cultivar comercial Comum-RS, em duas regiões fisiográficas distintas, visando à seleção de germoplasma com potencial produtivo e adaptativo para lançamento de novos cultivares.

\section{Material e Métodos}

Foram conduzidos dois experimentos em duas regiões fisiográficas do Rio Grande do Sul. O primeiro experimento foi conduzido na Estação Experimental Agronômica da Universidade Federal do Rio Grande do Sul (EEA), localizada a $30^{\circ} 05^{\prime} \mathrm{S}$ de latitude e $51^{\circ} 39^{\prime} \mathrm{W}$ de longitude, a $40 \mathrm{~m}$ de altitude do nível do mar e situada em Eldorado do Sul (RS), na região fisiográfica da Depressão Central do Rio Grande do Sul. Conforme classificação de Köppen (1948), o clima nessa região é do tipo Cfa (subtropical úmido, com verão quente e temperatura média do mês mais quente superior a $22^{\circ} \mathrm{C}$ ). A temperatura média anual é de $19,3^{\circ} \mathrm{C}$, com médias máximas de $24,6^{\circ} \mathrm{C}$ em janeiro e médias mínimas de $13,8^{\circ} \mathrm{C}$ em junho. A precipitação pluvial média anual fica em torno de $1.400 \mathrm{~mm}$ (Bergamaschi \& Guadagnin, 1990). O solo onde foi conduzido o experimento pertence à unidade de mapeamento Arroio dos Ratos e, pelo sistema brasileiro de classificação de solos, é classificado como Plintossolo Argilúvico Distrófico (FTd) (EMBRAPA, 1999).
O segundo experimento foi conduzido na Estação Experimental de Veranópolis do Centro de Pesquisa da Pequena Propriedade da FEPAGRO, Fundação Estadual de Pesquisa Agropecuária (EEV). A EEV localiza-se a 2856'S de latitude, $51^{\circ} 33^{\prime} \mathrm{W}$ de longitude, com altitude de $705 \mathrm{~m}$ do nível do mar, e pertence ao município de Veranópolis (RS), localizado na região fisiográfica da Encosta Superior do Nordeste. De acordo com a classificação de Köppen (1948), essa é uma região de transição entre os tipos Cfa e Cfb (clima temperado úmido, com chuvas bem distribuídas ao longo do ano). A temperatura média do mês mais quente do ano é de $22^{\circ} \mathrm{C}$, a temperatura média anual de $17,5^{\circ} \mathrm{C}$ e a média das temperaturas mínimas no mês de junho de $8,3^{\circ} \mathrm{C}$. A precipitação pluvial média anual nessa região é de 1.600 mm(IPAGRO, 1979). O solo na área experimental em Veranópolis pertence à unidade de mapeamento Ciríaco e, pelo sistema brasileiro de classificação de solos, é classificado como Chernossolo Argilúvico Férrico Típico (MTf), (EMBRAPA, 1999).

Em ambos os locais, foram avaliadas sete populações locais de azevém anual: um cultivar Uruguaia (LE-284), um Nova Zelândia (Eclipse) e um comercial Comum-RS (Tabela 1), totalizando dez tratamentos em um delineamento experimental de blocos casualizados, com quatro repetições.

Na EEA, cada parcela foi constituída de uma área de $3 \mathrm{~m}^{2}(1,5 \times 2 \mathrm{~m})$, enquanto na EEV a área foi de $6 \mathrm{~m}^{2}$ $(2 \times 3 \mathrm{~m})$ distantes $0,5 \mathrm{~m}$ das demais parcelas dentro do bloco e $1 \mathrm{~m}$ entre blocos. O solo foi preparado, corrigido e adubado de acordo com as recomendações técnicas da SBCS (Sociedade Brasileira de Ciência do Solo, 2004). A semeadura foi realizada no dia 22 de abril de 2004 na EEV e no dia 28 do mesmo mês na EEA. As populações foram semeadas em linhas espaçadas $0,1 \mathrm{~m}$ dentro de cada parcela.

No dia 28 de junho do mesmo ano, realizou-se a primeira adubação nitrogenada, com 50 kg de nitrogênio por hectare sob a forma de uréia, nos dois locais. Posteriormente, depois de cada corte (com exceção do último corte, quando não foi aplicado $\mathrm{N}$ ), foram aplicados $50 \mathrm{~kg} \mathrm{~N} / \mathrm{ha}$, totalizando $250 \mathrm{~kg}$ N/ha na EEA e 200 kg N/ha na EEV. A produção de forragem foi avaliada por meio de cortes de uma amostra de $0,5 \times 0,5 \mathrm{~m}$ por parcela, com auxílio de uma tesoura de esquila a $0,1 \mathrm{~m}$ acima do solo sempre que as plantas atingiram em torno de 0,2 m (Tabela 2). Após a retirada da amostra, as parcelas foram cortadas na altura do resíduo e em cada uma foi realizada a separação morfológica (folhas, colmos e inflorescências). Os componentes foram secos em estufa com ventilação forçada a $65^{\circ} \mathrm{C}$ até peso constante.

Os dados foram submetidos a análise de variância e as médias comparadas pelo teste de Duncan a 5\% de probabilidade. Também foi realizada uma análise conjunta dos dois experimentos para avaliação da produção de matéria seca 
Tabela 1 - Germoplasma de azevém avaliado na EEA e na EEV em 2004

\begin{tabular}{lccc}
\hline Acesso & Tipo & Procedência & Origem \\
\hline Comum-RS & Cv & RS, Brasil & Cultivar comercial - Brasil \\
Eclipse & Cv & RS, Brasil & Cultivar comercial - Nova Zelândia \\
LE-284 & Cv & Cruguai & Cultivar comercial - Uruguai \\
Casca & População & Casca, RS & FEPAGRO \\
Hulha & População & Hulha Negra, RS & FEPAGRO \\
Lavras & População & Lavras do Sul, RS & Fernando Adauto Loureiro de Souza \\
São Gabriel & População & São Grabriel, RS & FEPAGRO \\
Sarandi & População & Sarandi, RS & FEPAGRO \\
Trovão & População & - & FEPAGRO \\
Vacaria & População & Vacaria & FEPAGRO \\
\hline
\end{tabular}

EEA - Estação Experimental Agronômica (UFRGS); EEV - Estação Experimental de Veranópolis (FEPAGRO).

Tabela 2 - Datas dos cortes realizados na EEA e na EEV

\begin{tabular}{lcc}
\hline & EEA & EEV \\
\hline 1 o corte & $28 / 8 / 2004$ & $26 / 8 / 2004$ \\
2 o corte & $17 / 9 / 2004$ & $16 / 9 / 2004$ \\
3 o corte & $11 / 10 / 2004$ & $8 / 10 / 2204$ \\
4 o corte & $3 / 11 / 2004$ & $8 / 11 / 2004$ \\
5 o corte & $29 / 11 / 2004$ & - \\
\hline
\end{tabular}

de folhas (MSF) e de matéria seca total (MST) acumuladas. Todas as análises foram realizadas utilizando-se o aplicativo computacional SANEST (Alves et al., 1993).

\section{Resultados e Discussão}

A análise estatística da produção de MSF na EEA comprovou interação significativa entre populações e cortes ( $\mathrm{P}=0.00002)$ e, com exceção do quinto corte, em todos os demais houve diferenças significativas entre as populações (Tabela 3; Figura 1).

No primeiro corte, a população Casca, cultivares Comum-RS e LE-284, e a população Sarandi foram as mais precoces e diferiram apenas das populações Lavras e Hulha, que foram as menos produtivas. No segundo corte, a população Sarandi apresentou a maior produção e diferiu significativamente de todas as demais, enquanto o cultivar Comum-RS apresentou a menor produção, mas não diferiu estatisticamente das populações Trovão e Vacaria e do cultivar LE-284. No terceiro e quarto cortes, o cultivar Eclipse apresentou a maior produção, apesar de no quarto corte não ter diferido das populações Hulha, Lavras e Sarandi. Portanto, apresentou produção mais tardia em comparação às outras populações. No quarto e quinto cortes, o cultivar Comum-RS continuou com reduzida produtividade e manteve-se entre as populações menos produtivas. Finalmente, no quinto corte, não diferiu dos demais e apresentou a menor produção de forragem, em decorrência do final do ciclo da espécie. Apesar disso, o cultivar Eclipse, juntamente com a população Lavras, foram as de ciclo produtivo mais tardio.

Observou-se para produção de MST na EEA interação significativa entre populações e cortes $(\mathrm{P}=0,00020)$ (Tabela 4). No primeiro corte (Tabela 4), apesar de não ter diferenciado significativamente de outros materiais (populações Casca, Sarandi e cultivar LE-284), o cultivar Comum-RS destacou-se quanto à precocidade de produção de MST, o que justifica sua ampla utilização no Rio Grande do Sul e seu potencial de rápido crescimento inicial quando bem manejado. No segundo corte, a população Sarandi apresentou a maior produção de MST e não diferiu significativamente das populações Trovão, Casca e do cultivar Comum-RS. A população Vacaria, que não havia apresentado uma precocidade de produção no primeiro corte, continuou com baixa produção de MST e não diferiu dos cultivares Eclipse e LE-284 e das populações Lavras, Hulha e S. Gabriel. No terceiro corte, essa população apresentou numericamente as maiores médias de produção (1.394 kg MST/ha), juntamente com o segundo corte (1.380 kg MST/ha). Nessa avaliação, houve um grupo de materiais que apresentou maiores produções (populações Lavras, Comum-RS, Eclipse, Hulha, Sarandi, Vacaria, Trovão e LE-284), comprovando sua boa capacidade produtiva no período de maior crescimento dessa espécie.

Apesar de não ter diferido significativamente de outros materiais, a população São Gabriel apresentou a menor produção de MST, que contrastou com suas produções nos cortes anterior e posterior, indicando menor estabilidade de produção. No quarto corte, a população Sarandi continuou se destacando quanto à produção de MST, indicando boa estabilidade de produção, pois, desde o segundo corte apresentou boas produções de forragem (igual ou superior a todas as demais). A população Vacaria, no entanto, manteve sua tendência de baixa produção e não diferiu dos 
Tabela 3 - Produção média de matéria seca de folhas ( $\mathrm{kg} / \mathrm{ha})$ dos germoplasmas de azevém anual na EEA

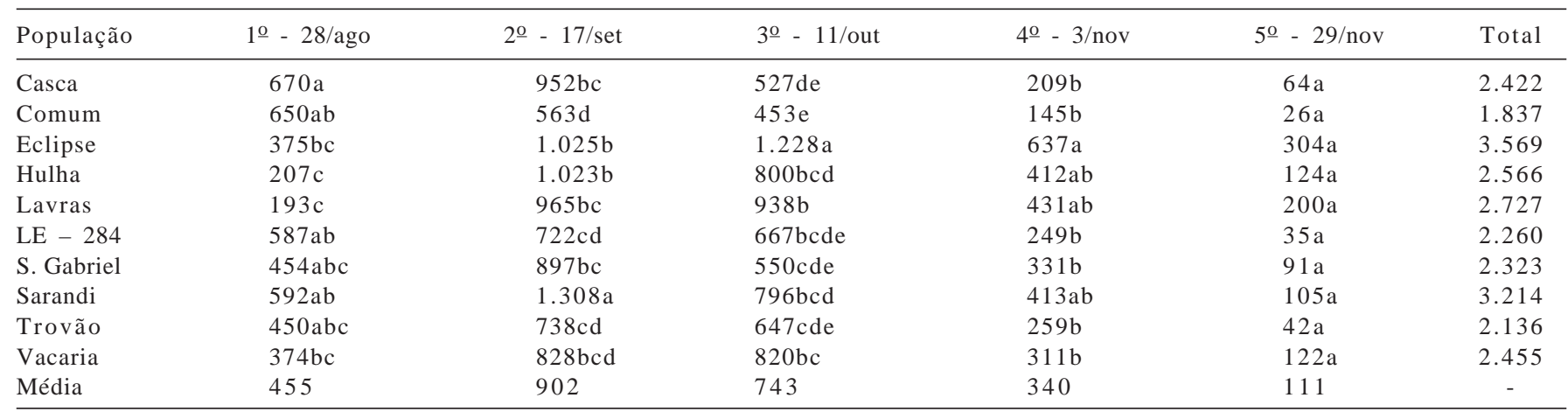

*Médias seguidas de mesma letra nas colunas não diferem pelo teste Duncan.

Tabela 4 - Produção média de matéria seca total (kg/ha) de germoplasmas de azevém anual na EEA

\begin{tabular}{|c|c|c|c|c|c|c|}
\hline População & $1^{0}-28$ /ago & $2^{\underline{o}}-17 /$ set & $3^{0}-11 /$ out & $4^{\mathrm{o}}-3 / \mathrm{nov}$ & $5 \underline{0}-29 /$ nov & Total \\
\hline Casca & 688ab & $1.529 \mathrm{abc}$ & $1.030 \mathrm{ac}$ & $1.301 \mathrm{abc}$ & $412 \mathrm{ab}$ & 4.960 \\
\hline Comum & $1.101 \mathrm{a}$ & $1.520 \mathrm{abc}$ & $1.619 \mathrm{a}$ & 716de & $210 b$ & 5.166 \\
\hline Eclipse & $375 b$ & $1.065 \mathrm{~cd}$ & $1.555 \mathrm{ab}$ & 879cde & $551 \mathrm{ab}$ & 4.425 \\
\hline Lavras & $193 b$ & $1.091 \mathrm{~cd}$ & $1.755 a$ & 1.173abcd & $932 a$ & 5.144 \\
\hline LE - 284 & $592 \mathrm{ab}$ & $1.279 \mathrm{bcd}$ & $1.356 \mathrm{abc}$ & $1.068 \mathrm{bcde}$ & $300 b$ & 4.595 \\
\hline S. Gabriel & $454 \mathrm{~b}$ & $1.378 \mathrm{bcd}$ & $955 c$ & $1.494 \mathrm{ab}$ & 492ab & 4.773 \\
\hline Vacaria & $374 b$ & $971 d$ & $1.395 a b c$ & $611 \mathrm{e}$ & $197 b$ & 3.548 \\
\hline Média & 513 & 1.380 & 1.394 & 1160 & 465 & - \\
\hline
\end{tabular}

*Médias seguidas de mesma letra nas colunas não diferem pelo teste Duncan.

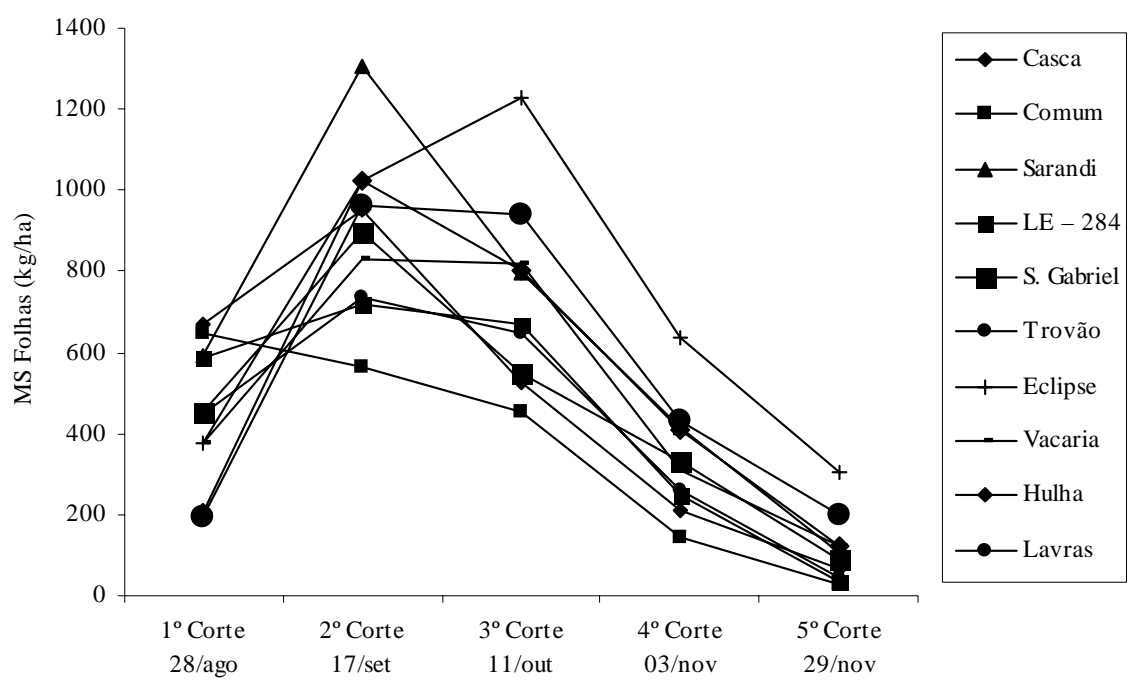

Figura 1 - Produção de matéria seca de folhas (kg/ha) de cultivares de azevém anual na EEA. 
cultivares Comum-RS, Eclipse e LE-284. No quinto e último cortes, a população Lavras destacou-se, embora não tenha diferido estatisticamente de outras populações (Hulha, Sarandi, S. Gabriel e cultivar Eclipse). Essa população, que apresentou baixa produção inicial, pode ter compensado essa falta de precocidade com maior produção no final do ciclo.

Em geral, a população Sarandi foi sempre uma das mais produtivas, com os maiores valores numéricos de MST durante o período experimental (6.349 kg/ha), seguida da população Trovão.

Na EEV, observaram-se diferenças significativas entre as populações $(\mathrm{P}=0.01479)$ e entre populações e cortes $(\mathrm{P}<0,00001)$ para produção de matéria seca de folhas (MSF) (Tabela 5).

No primeiro corte (Tabela 5), destacaram-se as populações Trovão, Casca e cultivar comercial Comum-RS, que não diferiram estatisticamente do cultivar LE-284 e da população São Gabriel, comprovando serem materiais de ciclos produtivamente mais precoces. Nesse primeiro corte, o cultivar Eclipse e a população Vacaria foram os que apresentaram numericamente as menores produções, embora não tenham se diferenciado da população Lavras, indicando que pode apresentar crescimento inicial mais lento em comparação aos demais cultivares. No segundo corte, praticamente não ocorreram diferenças entre os tratamentos, com exceção do cultivar LE-284 e da população Sarandi, que se mostraram superiores ao cultivar ComumRS. No terceiro corte, o cultivar Eclipse recuperou-se e apresentou melhor desenvolvimento, diferen- ciando-se da população Trovão e do cultivar Comum-RS, o que indica ciclo produtivo mais tardio. Por outro lado, o cultivar Comum-RS novamente apresentou menores valores e sua produção foi significativamente inferior à das populações Lavras, Sarandi e Trovão. Finalmente, no quarto e último corte, o cultivar Eclipse continuou com melhor produção de MSF, indicando ser de ciclo produtivo mais tardio. Nesse corte, não foram observadas diferenças entre todas as outras populações ou cultivares.

De modo geral, nas populações Casca e São Gabriel os valores de produção de MSF (Tabela 5; Figura 2) foram altos e constantes ao longo da estação de crescimento. Observou-se significância $(\mathrm{P}<0,00001)$ para produção de matéria seca total (MST) na EEV, assim como para a interação populações $\times$ cortes (Tabela 6 ).

No primeiro corte, observou-se diferença significativa entre as populações. O cultivar Comum-RS apresentou a maior produção de MST, indicando ser o mais precoce e diferindo significativamente de todas as demais populações. O cultivar Eclipse e a população Vacaria apresentaram as menores produções, mas diferiram de Hulha, Lavras, S. Gabriel e Sarandi, confirmando sua condição de acumular forragem mais tardiamente, como discutido anteriormente. No segundo e terceiro cortes, não houve diferença significativa entre as populações e todos os cultivares tiveram produções semelhantes nesse período da estação de crescimento. Portanto, a diferenciação entre eles, quanto ao acúmulo de MST, esteve muito mais relacionada à distribuição da produção ao longo do ciclo que a diferenças em potencial produtivo. No quarto corte, as diferenças foram significativas entre as populações; a população Lavras apresentou a maior produção e foi semelhante apenas à Sarandi e, repetindo o baixo desempenho observado anteriormente, a população Vacaria e a cultivar Comum-RS mantiveram-se entre as menos produtivas.

A população Lavras apresentou elevada produção de MST durante o crescimento (Tabela 6). Entretanto, esta produção foi construída principalmente no último corte, portanto, a produção de forragem desta população é mais tardia na estação de crescimento. O cultivar Comum-RS, no entanto, apesar da boa produção de MST ao final do ciclo produtivo, apresentou maior acúmulo de forragem no

Tabela 5 - Produção média de matéria seca de folhas ( $\mathrm{kg} / \mathrm{ha}$ ) de germoplasmas de azevém anual em quatro cortes na EEV

\begin{tabular}{|c|c|c|c|c|c|}
\hline População & $1^{o}-26 /$ ago & $2^{o}-16 /$ set & $3^{\text {o }}-8 /$ out & 4 - $-8 /$ nov & Total \\
\hline Comum & $754 a$ & $207 b$ & $362 c$ & $98 b$ & 1.521 \\
\hline Hulha & $550 \mathrm{bc}$ & 402ab & 587abc & $235 b$ & 1.774 \\
\hline Lavras & $347 c d$ & $451 \mathrm{ab}$ & 762ab & $296 b$ & 1.856 \\
\hline LE - 284 & 740ab & $484 \mathrm{a}$ & 560 abc & $1.59 \mathrm{~b}$ & 1.943 \\
\hline S. Gabriel & $677 a b$ & 442ab & $574 a b c$ & $2.12 \mathrm{~b}$ & 1.905 \\
\hline Vacaria & $238 d$ & 279ab & $610 a b$ & $54 \mathrm{~b}$ & 1.181 \\
\hline Média & 582 & 385 & 601 & 212 & - \\
\hline
\end{tabular}

*Médias seguidas de mesma letra nas colunas não diferem entre si pelo teste de Duncan. 


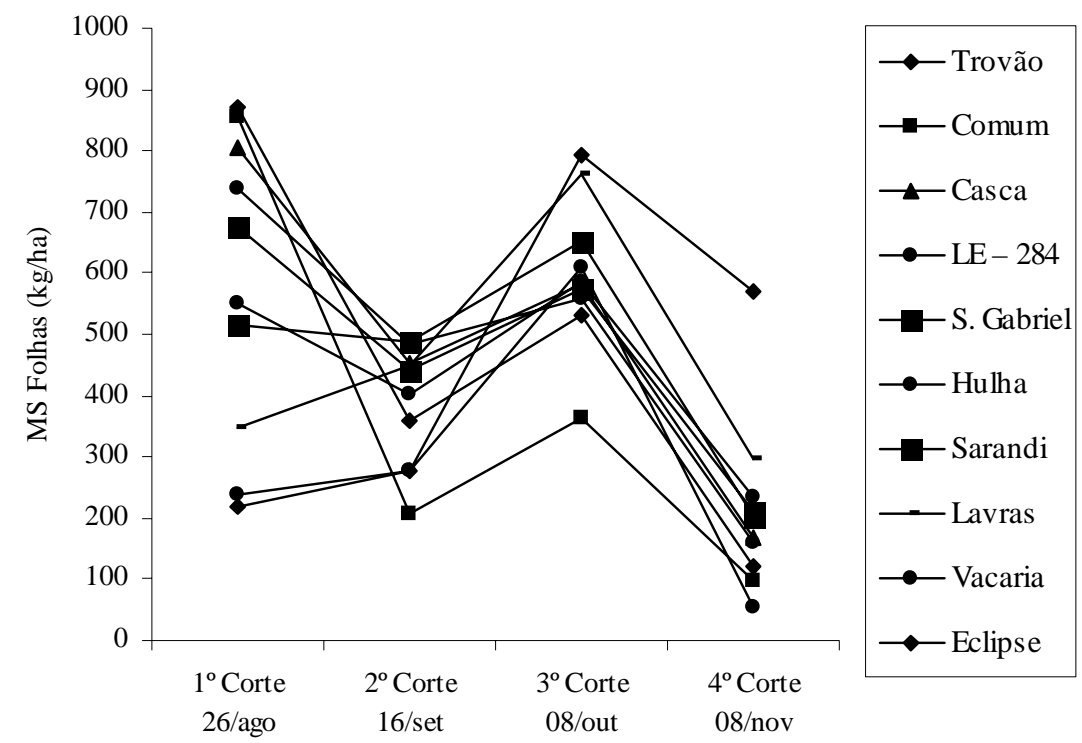

Figura 2 - Produção de matéria seca de folhas (kg/ha) de cultivares de azevém anual em cada corte na EEV.

Tabela 6 - Produção média de matéria seca total (kg/ha) de germoplasmas de azevém anual

\begin{tabular}{|c|c|c|c|c|c|}
\hline População & $1^{\underline{o}}-26 /$ ago & $2^{\underline{o}}-16 /$ set & $3^{\text {o }}-8 /$ out & $4 \underline{0}-8 /$ nov & Total \\
\hline Casca & $1.044 \mathrm{~b}$ & $750 a$ & $1.004 \mathrm{a}$ & $1.646 \mathrm{~cd}$ & 4.444 \\
\hline Comum & $1.656 a$ & $366 a$ & $1.030 \mathrm{a}$ & $1.143 \mathrm{ef}$ & 4.195 \\
\hline Eclipse & $220 \mathrm{e}$ & $336 a$ & $1.021 \mathrm{a}$ & 1.576 cde & 3.153 \\
\hline Lavras & $347 \mathrm{de}$ & $451 \mathrm{a}$ & $1.132 \mathrm{a}$ & $2.580 \mathrm{a}$ & 4.510 \\
\hline LE - 284 & 799bcd & $737 a$ & $1.210 \mathrm{a}$ & $1.710 \mathrm{~cd}$ & 4.456 \\
\hline São Gabriel & 697bcde & $612 \mathrm{a}$ & $1.036 \mathrm{a}$ & $2.026 \mathrm{bc}$ & 4.371 \\
\hline Vacaria & $238 \mathrm{e}$ & $295 a$ & $862 \mathrm{a}$ & $762 \mathrm{f}$ & 2.157 \\
\hline Média & 704 & 531 & 1048 & 1681 & - \\
\hline
\end{tabular}

*Médias seguidas de mesma letra nas colunas não diferem entre si pelo teste Duncan.

início da estação de crescimento. Complementarmente, as populações São Gabriel e Sarandi, além de bons níveis de produção de MST ao final da estação de crescimento, acumularam essa produção mais uniformemente ao longo do ciclo. A produção de MST da população Vacaria foi baixa $(2157 \mathrm{~kg} / \mathrm{ha})$ e manteve-se sempre entre as baixas ao longo do ciclo de crescimento.

O cultivar Comum-RS tem sido amplamente distribuído e utilizado no Rio Grande do Sul há muitos anos, em virtude de sua ampla adaptação. No entanto, nem sempre tem apresentado produções de forragem superiores a de outros materiais avaliados. Por exemplo, na década de 70, em teste de produção de MST em São Gabriel (RS), sua produtividade foi inferior a de outros materiais avaliados. O mesmo foi observado em experimento conduzido em Vacaria (RS) (Fontaneli, 1984), o que pode indicar que já naquela época poderiam existir materiais mais produtivos, como os cultivares Astro e Ariki. No entanto, uma boa característica do cultivar Comum-RS é sua produção no início do ciclo de crescimento (Tabelas 3, 4, 5 e 6), contudo, essa espécie tem baixa produção no final do ciclo, o que torna importante o investimento no melhoramento genético da espécie, uma vez que existe germoplasma adaptado às condições ambientais do Sul do País e com melhor distribuição estacional da produção.

Na maioria das análises, houve diferenças significativas entre as populações, além de interação significativa entre população e corte. Portanto, é possível que exista variabilidade entre as populações avaliadas e que haja material suficiente e variável para realização de seleção.

Castro et al. (1999) analisaram três populações de azevém provenientes do Rio Grande do Sul, além do cultivar LE-284, quanto a caracteres agronômicos de interesse como: diâmetro de cobertura do solo, número de afilhos, ciclo, área foliar total, peso de folhas, peso de colmo, relação folha/ colmo e matéria seca total, assim como a correlação entre 
Tabela 7 - Produção total matéria seca de folhas $(\mathrm{kg} / \mathrm{ha})$ de germoplasmas de azevém anual

\begin{tabular}{lllc}
\hline População & EEA & EEV & Média \\
\hline Casca & $2.424 \mathrm{~cd}$ & $2.009 \mathrm{a}$ & 2.216 \\
Comum & $1.837 \mathrm{e}$ & $1.522 \mathrm{ab}$ & 1.680 \\
Eclipse & $3.572 \mathrm{a}$ & $1.865 \mathrm{a}$ & 2.718 \\
Hulha & $2.567 \mathrm{~cd}$ & $1.774 \mathrm{a}$ & 2.171 \\
Lavras & $2.728 \mathrm{bc}$ & $1.858 \mathrm{a}$ & 2.293 \\
LE-284 & $2.261 \mathrm{cde}$ & $1.944 \mathrm{a}$ & 2.102 \\
S. Gabriel & $2.324 \mathrm{cde}$ & $1.906 \mathrm{a}$ & 2.115 \\
Sarandi & $3.215 \mathrm{ab}$ & $1.862 \mathrm{a}$ & 2.538 \\
Trovão & $2.136 \mathrm{de}$ & $1.886 \mathrm{a}$ & 2.011 \\
Vacaria & $2.456 \mathrm{~cd}$ & $1.182 \mathrm{~b}$ & 1.819 \\
Média & 2.552 & 1.781 & - \\
\hline
\end{tabular}

*Médias seguidas de mesma letra nas colunas não diferem entre si pelo teste de Duncan.

estes caracteres. Os autores observaram alta variabilidade para as características estudadas e correlação positiva entre todos os caracteres, exceto para o caráter ciclo, o que permite que estas características sejam agregadas em uma população melhorada.

McLean \& Watson (1992) avaliaram em quatro cultivares de azevém anual a variação e a resposta de seleção para o caráter período de antese em três anos no estado do Mississipi (EUA) e verificaram a existência de variação genética suficiente após dois ciclos de seleção. Neste trabalho também foi observada grande variação no período de florescimento na maioria das populações. Casler (1995) também encontrou variação nos caracteres vigor da plântula, largura da folha, ferrugem da coroa e produção de forragem em 375 acessos, que representam a coleção inteira de azevém perene do USDA. Esse autor concluiu que, mesmo após 60 anos de intensivo melhoramento, a variação perdida foi mínima.

Uma vez que os experimentos foram conduzidos em dois locais diferentes -Eldorado do Sul, na EEA, e em Veranópolis, na EEV - no ano de 2004, realizou-se uma análise conjunta para produção de MSF e MST ao final do ciclo de crescimento.

Na análise conjunta da produção de MSF, verificou-se interação significativa entre os fatores população e local, por isso, realizou-se uma comparação dos dados por meio das médias das populações dentro de cada local. Na EEA, a análise indicou o cultivar Eclipse e a população Sarandi como as mais produtivas (Tabela 7). O cultivar Comum-RS destacou-se negativamente com a menor produção ao final do ciclo de crescimento, juntamente com as populações Trovão e São Gabriel, e com o cultivar LE-284, que, por sua vez, não diferiram entre si. Na EEV, praticamente não houve diferenças entre os cultivares avaliados. Apenas a população Vacaria teve produção significativamente menor que as demais, com exceção do cultivar Comum-RS.
Tabela 8 - Análise conjunta da produção total de matéria seca total $(\mathrm{kg} / \mathrm{ha})$ de germoplasmas de azevém anual

\begin{tabular}{lclc}
\hline População & EEA & EEV & Média \\
\hline Casca & 4.960 & 4.446 & $4.703 \mathrm{~b}$ \\
Comum & 5.166 & 4.198 & $4.682 \mathrm{~b}$ \\
Eclipse & 4.425 & 3.154 & $3.789 \mathrm{c}$ \\
Hulha & 4.976 & 3.779 & $4.377 \mathrm{bc}$ \\
Lavras & 5.146 & 4.512 & $4.829 \mathrm{ab}$ \\
LE-284 & 4.596 & 4.458 & $4.527 \mathrm{~b}$ \\
S. Gabriel & 4.775 & 4.372 & $4.574 \mathrm{~b}$ \\
Sarandi & 6.350 & 4.446 & $5.398 \mathrm{a}$ \\
Trovão & 5.201 & 4.134 & $4.668 \mathrm{~b}$ \\
Vacaria & 3.550 & 2.159 & $2.855 \mathrm{~d}$ \\
Média & $4.915 \mathrm{~A}$ & $3.966 \mathrm{~B}$ & - \\
\hline
\end{tabular}

* Médias seguidas de mesma letra, maiúsculas nas linhas, e minúsculas nas colunas, não diferem entre si pelo teste de Duncan.

Na análise conjunta da produção total de MST (Tabela 8), não ocorreu interação significativa entre os fatores população e local, indicando que as populações apresentaram mesmo comportamento relativo em ambos os locais (Tabela 8). Além disso, a produção de folhas discrimina melhor as populações, o que é importante para a seleção (Tabelas 7 e 8). Como a interação população $\times$ local não foi significativa para MST, realizou-se apenas a comparação dos dados utilizando-se as médias das populações e a produção média total de cada local. Na análise conjunta dos locais (Tabela 8), não ocorreram diferenças significativas para a produção de MST entre as populações Sarandi e Lavras; a população Sarandi superou todas demais. O cultivar Eclipse apresentou baixa produção na média dos dois locais e não diferiu da população Hulha, mas foi superior à população Vacaria, que apresentou a menor produção.

A maior produção de MST ocorreu no experimento conduzido em Eldorado do Sul, na EEA (Tabela 8), o que não era esperado, pois as condições de Veranópolis são mais favoráveis para o desenvolvimento do azevém, uma gramínea bem adaptada ao clima subtropical temperado (Nelson et al., 1997). Esse resultado pode ser atribuído ao fato de que em Veranópolis o clima é de transição entre os tipos cfa (subtropical úmido com temperatura média do mês mais quente superior a $22^{\circ} \mathrm{C}$ ) e cfb (clima temperado úmido com temperatura média do mês mais quente inferior a $22^{\circ} \mathrm{C}$ ). Em Eldorado do Sul, no entanto, o clima da região é do tipo cfa (Köeppen, 1948).

\section{Conclusões}

Há uma grande variabilidade dentro da espécie, sobretudo quanto à distribuição da produção de forragem ao longo do ciclo. A produção de forragem do cultivar Comum-RS, em ambos os locais, concentrou-se no início da estação de 
crescimento. A população Sarandi, por sua vez, apresentou elevado potencial produtivo e boa distribuição da produção de forragem ao longo do ciclo em Eldorado do Sul. Em Veranópolis, as populações Lavras, Sarandi e São Gabriel apresentaram elevado potencial produtivo. O cultivar Eclipse apresentou a melhor produção de MSF e sua produção se concentrou no final do ciclo produtivo, confirmando a característica de desenvolvimento tardio.

\section{Literatura Citada}

ALVES, M.I.F.; MACHADO, A.A.; ZONTA, E.P. Tópicos especiais de estatística experimental utilizando o SANEST (Sistema de Análise Estatística para Microcomputadores). In: SIMPÓSIO DE ESTATÍSTICA APLICADA À EXPERIMENTAÇÃO AGRONÔMICA, 5.; REUNIÃO ANUAL DA SOCIEDADE INTERNACIONAL DE BIOMETRIA, 38., 1993, Porto Alegre. Anais... Porto Alegre: Departamento de Estatística da Universidade Federal do Rio Grande do Sul, 1993. p.1-110.

BERGAMASCHI, H.; GUADAGNin, M.R. Agroclima da estação experimental agronômica. Porto Alegre: Departamento de Plantas Forrageiras e Agrometeorologia da UFRGS, 1990. 91p.

CASLER, M.D. Patterns of vatiation in a collection of perennial ryegrass accessions. Society of America, v.34, n.4, p.1169, 1995.

CASTRO, C.M.; OLIVEIRA, A.C.; MAIA, M.S. et al. Análise da variabilidade em populações de azevém anual (Lolium multiflorum L.) com relação a caracteres de interesse forrageiro. In: REUNIÃO ANUAL DA SOCIEDADE BRASILEIRA DE ZOOTECNIA, 36, Porto Alegre, 1999. Anais... Porto Alegre, 1999. (CD-ROM).

CONAB. [2007]. Produção agropecuária: safra de grãos 2006/ 2007. Disponível em: <www.conab.gov.br/conabweb>. Acesso em: 10/6/2007.
EMPRESA BRASILEIRA DE PESQUISA AGROPECUÁRIA EMBRAPA Sistema Brasileiro de Classificação de Solos. Brasília: Centro Nacional de Pesquisa de Solos, 1999. 412p. (Documentos, 5).

FONTANELI, R.S. Azevém anual. In: ENCONTRO DE INTEGRAÇÃO LAVOURA-PECUÁRIA DO PLANALTO MÉDIO RIO-GRANDENSE, 1984, Passo Fundo. Anais... Passo Fundo, Universidade de Passo Fundo, 1984. p.139-150.

GILLET, M. Gramíneas forrageiras. Zaragoza: Acribia, 1984. 353p.

IPAGRO. Observações Meteorológicas no Estado do Rio Grande do Sul. Porto Alegre: IPAGRO, 1979. (Boletim Técnico, 3).

KÖEPPEN, W. Climatologia: con um estúdio de los climas de la Tierra. México: Fondo de Cultura Economica, 1948. 478p.

MCLEAN, S.D.; WATSON JR, C.E. Divergent selection for anthesis date in annual ryegrass. Crop Breeding, Genetics \& Cytology, v.32, n.4, p.847, 1992.

NELSON, C.J.; MOSER, L.E. Plant factors affecting forage quality. In: FAHEY JR., G.C. (Ed.) Forage quality, evaluation, and utilization. Madison: American Society of Agronomy / Crop Science Society of America / Soil Science Society of America, 1994. p.115-154.

NELSON, L.R. Pest management in ryegrass. In: SYMPOSIUM ON ANNUAL RYEgRASS, 1995, Tyler. Proceedings... Tyler: Texas A\&M University Agriculture research and Extension Center - Overton Texas Agricultural Experiment Station and Texas Agricultural Extension Service, 1995. p.100-105.

NELSON, L.R.; PHILLIPS, T.D.; WATSON, C.E. Plant breeding for improved production in annual ryegrass. In: ROUQUETTE, F.M.; NELSON, L.R. (Eds.) Ecology, production, and management of Lolium for forage in the USA. Madison: Crop Science Society of America, 1997. 138p.

SANTOS, H.P.; FONTANELI, R.S.; BAIER, A.C. et al. Principais forrageiras para integração lavoura-pecuária, sob plantio direto, nas regiões Planalto e Missões do Rio Grande do Sul. Passo Fundo: Embrapa, 2002. 142p.

SOCIEDADE BRASILEIRA DE CIÊNCIA DO SOLO - SBCS. Comissão de Química e Fertilidade do Solo. Manual de adubação e de calagem para os Estados do Rio Grande do Sul e de Santa Catarina. 10.ed. Porto Alegre: 2004. 400p 